\title{
Characterizing the Effect of Foliar Lipo-chitooligosaccharide Application on Sudden Death Syndrome and Sclerotinia Stem Rot in Soybean
}

David A. Marburger, Department of Plant and Soil Sciences, Oklahoma State University, Stillwater, 74078; Jaime F. Willbur ${ }^{\dagger}$ and Maria E. Weber, Department of Plant Pathology, University of Wisconsin-Madison, 53706; Jean-Michel Ané, Departments of Agronomy and Bacteriology, University of Wisconsin-Madison, 53706; Medhi Kabbage, Department of Plant Pathology, University of Wisconsin-Madison, 53706; Shawn P. Conley, Department of Agronomy, University of Wisconsin-Madison, 53706; and Damon L. Smith, Department of Plant Pathology, University of Wisconsin-Madison, 53706

Accepted for publication 12 January 2018.

\section{Abstract}

Lipo-chitooligosaccharides (LCOs) are signal molecules produced by plant root endosymbionts and have been identified, formulated, and marketed as growth-promoting adjuvants for soybean (Glycine max [L.] Merr.). Experiments were conducted under controlled environmental conditions to characterize the effects of foliar LCO applications on early symptom development of sudden death syndrome (SDS), caused by Fusarium virguliforme, and Sclerotinia stem rot (SSR), caused by Sclerotinia sclerotiorum. Treatment factors for the SDS experiment included two soybean cultivars (Sloan and CH2105R2), two inoculation levels (noninoculated control and inoculated), and two LCO applications (control and foliar
LCO application), whereas two experimental soybean lines (91-38 and 91-44) and two LCO applications (water control and foliar LCO application) were used in the SSR experiment. The LCO application did not significantly influence SDS root symptom severity or earlyseason growth characteristics. However, on the susceptible line $(P=0.01)$ and with LCO application $(P=0.03)$, significantly larger SSR lesions developed compared with the nontreated control and resistant line. These results suggest foliar-applied LCOs have a limited effect on early root symptom development caused by $F$. virguliforme but increase stem symptom development caused by S. sclerotiorum.
Lipo-chitooligosaccharides (LCOs) are signal molecules involved in the early stages of the rhizobia-legume symbiosis development (Venkateshwaran et al. 2013). Plant roots exude signal molecules, mainly flavonoids, isoflavonoids, and betaines (Cesco et al. 2010; Mandal et al. 2010). The perception of these signals by the rhizobia, through nucleotide oligomerization domain-like receptor proteins, induces the expression of structural nod genes, which leads to the production of LCOs (also known as Nod factors when produced by rhizobia). These diffusible LCOs are perceived by legume hosts at very low concentrations (micromolar to picomolar concentrations), are the main basis of host specificity in the rhizobia-legume association, and are generally required for root infection, nodule development, and subsequent $\mathrm{N}_{2}$ fixation. LCOs are composed of a tri- to penta-chitin backbone with an $\mathrm{N}$-acyl group at the nonreducing end and can possess a variety of substitutions along the chitin backbone. In soybean (Glycine max [L.] Merrill), a symbiotic relationship is often formed with the soil bacterium Bradyrhizobium japonicum, and the main Nod factor produced by the bacterium is $\mathrm{Bj}-\mathrm{V}\left(\mathrm{C}_{18: 1}, \mathrm{MeFuc}\right)$ (Duzan et al. 2005). LCOs are also produced by arbuscular mycorrhizal fungi (Maillet et al. 2011) and perceived by rice and legumes (Sun et al. 2015).

${ }^{\dagger}$ Corresponding author: Jaime F. Willbur; E-mail: jfwillbur@gmail.com

Funding: Funding was provided by the Wisconsin Soybean Marketing Board.

D. A. Marburger and J. F. Willbur contributed equally to this work.

(C) 2018 The American Phytopathological Society
LCOs have been found to stimulate seed germination (Zhang and Smith 2002), promote seedling development (Smith et al. 2002), stimulate root colonization by arbuscular mycorrhizal fungi (Xie et al. 1995), and cause cell division and embryogenesis (Spaink 1996). Furthermore, foliar-applied LCOs have been shown to increase the photosynthetic rates of soybean, common bean (Phaseolus vulgaris L.), corn (Zea mays L.), rice (Oryza sativa L.), canola (Brassica napus L.), apple (Malus domestica Borkh), and grape (Vitis vinifera L.) (Smith et al. 2002). This increase in photosynthetic rate led to a $40 \%$ soybean seed yield increase under field conditions (Smith et al. 2002). In today's soybean production, a foliar-applied, commercially available product containing LCOs (Ratchet, Monsanto BioAg, St. Louis, MO) is being marketed for reasons listed above.

LCOs are also similar in structure to chitooligosaccharides (COs), which are often derived from fungal and insect cell walls. COs are an example of a microbe-associated molecular pattern (MAMP), and these are known to activate plant defense responses including pattern-triggered immunity (Gough and Cullimore 2011). The presence of LCOs has also been known to indirectly elicit isoflavonoid phytoalexins (i.e., antimicrobial compounds known to accumulate rapidly at areas of pathogen infection) (Gough and Cullimore 2011). Some research has also examined the interaction between the presence of LCOs and disease development. A study by Duzan et al. (2005) showed the application of the Nod factor $\mathrm{Bj}-\mathrm{V}\left(\mathrm{C}_{18: 1}, \mathrm{MeFuc}\right)$ to soybean induced resistance to powdery mildew, caused by the fungus Microsphaera diffusa. Detection of bacterial flagellin (i.e., another example of MAMP) by a plant activates plant defense responses, including the production of reactive oxygen species (ROS). Liang et al. (2013) found adding purified Nod factor from B. japonicum to 
soybean leaves reduced ROS production by $25 \%$. Also, the same treatment to Arabidopsis thaliana leaves resulted in decreased ROS production, but the suppressive effect by the Nod factor was slower and weaker compared with soybean (Liang et al. 2013). These results counter those by Duzan et al. (2005), suggesting the presence of Nod factors may lead to increased infection by bacteria on soybean.

Soybean is affected by many pathogens, including Fusarium virguliforme O'Donnell \& T. Aoki and Sclerotinia sclerotiorum (Lib.) de Bary. $F$. virguliforme is the causal agent of soybean sudden death syndrome (SDS). Since its discovery in 1971, SDS has spread to much of the soybean-growing region of the United States. (Hartman et al. 2015). The fungus infects soybean roots early in the growing season, as early as 14 days after planting (Leandro et al. 2012), but artificial inoculation studies have suggested infection can occur on even younger seedlings (Navi and Yang 2008). Foliar symptoms develop later in the growing season (i.e., mid-reproductive growth stages) because of phytotoxins secreted by the fungus and translocated through the xylem in the roots to the leaves.

Soybean is also among more than 400 host species impacted by S. sclerotiorum, the causal agent of Sclerotinia stem rot (SSR) (Boland and Hall 1994). S. sclerotiorum overwinters in the soil as melanized sclerotia. During extended periods of cool, moist conditions, apothecia develop and produce infectious ascospores, which infect soybean flowers (Grau and Hartman 2015; Peltier et al. 2012). Owing to its broad host range and persistence in the soil, management of this disease remains of importance in many soybean-growing regions. At the molecular level, responses to $S$. sclerotiorum and rhizobia both regulate the production of ROS (Ranjan et al. in press). In a separate study, silencing the expression of an NADPH oxidase (GmRBOH-VI) in soybean led to an enhanced resistance to $S$. sclerotiorum and an increased drought tolerance but a decreased nodulation rate (Ranjan et al. in press).

Both SDS and SSR consistently rank in the top 10 soybean diseases impacting U.S. soybean yields. SDS ranked among the top 10 of soybean yield-suppressing diseases in the United States in 11 of 12 years from 1996 to 2007, and it often ranked second to fifth in those years (Wrather and Koenning 2009). Further work by Koenning and Wrather (2010) showed yield loss attributed to SDS totaled 1.5 million metric tons from 2008 to 2009, making it the fifth most yieldsuppressing soybean disease across those two years. From 1996 to 2009, it was estimated that SSR contributed more than 6.8 million metric tons in U.S. soybean yield loss, resulting in $\$ 1.9$ billion in lost revenue for producers (Koenning and Wrather 2010; Wrather and Koenning 2009). Another 2.2 million metric tons in yield loss was attributed to SSR from 2010 to 2014 (Bradley et al. 2017). In 2014, SDS ranked second and SSR ranked fourth in overall soybean yield reductions owing to disease (Bradley et al. 2017).

To our knowledge, controlled research studies examining interactions between LCOs and $F$. virguliforme and S. sclerotiorum, along with their effect on disease development and soybean growth, have not yet been performed. Therefore, the objectives of this study were (i) to characterize interactions between foliar-applied LCOs and $F$. virguliforme on early soybean root disease symptoms and early soybean growth characteristics and (ii) to characterize interactions between S. sclerotiorum and foliar-applied LCOs on early soybean stem lesion development. Our null hypotheses are as follows: (i) foliar application of LCOs will not affect early soybean root disease symptom development caused by $F$. virguliforme, and (ii) foliar application of LCOs will not increase early soybean stem symptoms caused by $S$. sclerotiorum.

\section{Experimental Design for Trials Examining $F$. virguliforme}

Single-spore cultures from three $F$. virguliforme isolates (00-11-183, NRRL22823, and Soy-1) were grown on potato dextrose agar (potato dextrose agar [dehydrated]; Fisher Scientific, Pittsburg, PA) for 14 days at $23 \pm 2^{\circ} \mathrm{C}$ with 12 -h diurnal light. Only one $F$. virguliforme isolate (Soy-1) originated in Wisconsin. The Soy-1 isolate was recovered from soybean, and polymerase chain reaction (PCR) was performed on extracted DNA using ITS4 (TCCTCCGCTTATTGATATGC) and ITS5 (GGAAGTAAAAGTCGTAACAAGG) primers targeting the internal transcribed spacer region of the ribosomal DNA (White et al. 1990). The PCR program included initial denaturation at $95^{\circ} \mathrm{C}$ for $2 \mathrm{~min}$ followed by 30 cycles of $95^{\circ} \mathrm{C}$ for $20 \mathrm{~s}, 55^{\circ} \mathrm{C}$ for $25 \mathrm{~s}$, and $72^{\circ} \mathrm{C}$ for $50 \mathrm{~s}$; final extension was performed at $72^{\circ} \mathrm{C}$ for $10 \mathrm{~min}$ (White et al. 1990). Resulting products were then sequenced, and sequences had $98 \%$ homology with $F$. virguliforme sequences in GenBank. The remaining two $F$. virguliforme isolates originated in Indiana and were recovered from soybean plants as well. PCR was performed on extracted DNA from the isolates using the F6-3 forward primer (GTAAGTGAGATTTAGTCTAGGGTAGGTGAC) and R9 reverse primer (CCATCCGTCTGGGAATTTTAACTA) developed by Wang et al. (2015). The PCR cycling conditions were set at one cycle at $94^{\circ} \mathrm{C}$ for $3 \mathrm{~min}$, followed by 35 cycles of $30 \mathrm{~s}$ at $94^{\circ} \mathrm{C}, 30 \mathrm{~s}$ at $65^{\circ} \mathrm{C}$, and $30 \mathrm{~s}$ at $72^{\circ} \mathrm{C}$, and a final extension for $5 \mathrm{~min}$ at $72^{\circ} \mathrm{C}$ (Wang et al. 2015). The resulting products were sequenced and compared with sequences in GenBank to confirm the identity as $F$. virguliforme. A modified version of the cornmeal-sand medium described by McLean and Lawrence (1993) was used as the carrier and was prepared 30 days before the establishment of the greenhouse experiment. Sand $(950 \mathrm{~g})$, yellow cornmeal $(50 \mathrm{~g})$, and distilled water $(150 \mathrm{ml})$ were added to an autoclavable bag and mixed. This step was repeated two times for each isolate and six times for a noninoculated control to achieve the desired amount of carrier. All media were autoclaved on two consecutive days for $60 \mathrm{~min}$ at $121^{\circ} \mathrm{C}$. The sterilized cornmeal-sand medium was infested adding 25 blocks (each $1 \mathrm{~cm}^{2}$ ) cut from infested agar on a standard-sized Petri plate to one autoclavable bag containing $950 \mathrm{~g}$ of sand and $50 \mathrm{~g}$ of cornmeal. Infesting the cornmeal-sand medium was performed individually for each isolate. All infested and noninfested media were incubated at $22^{\circ} \mathrm{C} \pm 1{ }^{\circ} \mathrm{C}$ with 12 -h diurnal light for 30 days. Bags were shaken every 3 to 4 days to provide more uniform fungal growth. Immediately before use in the greenhouse experiment, the infested cornmeal-sand medium from all three $F$. virguliforme isolates was mixed.

A greenhouse experiment was conducted at the University of Wisconsin-Madison from March to June in 2015. Two separate runs (i.e., repetitions) of this experiment were performed. For each run, there were six replications of treatments organized in a split-split-plot arrangement with the whole plot factor arranged as a completely randomized design. The whole plot factor consisted of two inoculation treatments: a control and inoculation with $F$. virguliforme. Subplots consisted of two LCO treatments: one control and one application of LCOs. Subsubplots (i.e., the experimental unit) consisted of two cultivars: Sloan (public cultivar) and CH2105R2 (Channel brand, Monsanto). The cultivar Sloan was chosen owing to its susceptibility to $F$. virguliforme (Tande et al. 2014; Ziems et al. 2006), whereas cultivar CH2105R2 was chosen because of its popularity owing to high yield potential and adaptability to Wisconsin (personal observation). This cultivar is described as partially resistant to $F$. virguliforme according to Channel brand SDS rating information (Channel 2014). The CH2105R2 cultivar is reported as a 2 on a 1 to 9 scale, with 1 indicating most resistant.

At the time of the run establishment, both infestation treatments were prepared by combining their respective cornmeal-sand media with Metro Mix potting soil (Sun Gro Horticulture, Agawam, MA) in a ratio of 1 part cornmeal-sand medium to 3 parts potting soil. The resulting cornmeal-sand-potting soil mixture was used to fill individual Cone-tainers (Stuewe and Sons, Tangent, OR). Cone-tainers 
measured $6.5 \mathrm{~cm}$ in diameter and $25.5 \mathrm{~cm}$ in depth. Two seeds were planted into each Cone-tainer to ensure the growth of at least one plant, and the number of seedlings was reduced to one, where appropriate, 7 days after planting. Four Cone-tainers, representing the four combinations of the two subplot and two subsubplot factors within each inoculation treatment, were placed in a $15-\mathrm{cm}$ diameter pot on a greenhouse bench. Each pot was placed in an aluminum tray, and the 24 pots with aluminum trays (i.e., the four combinations of the two subplot and two subsubplot factors $\times$ six replications) were randomly assigned to positions on a greenhouse bench. The aluminum trays were rotated every 7 days to mitigate potential greenhouse effects.

For each run, plants were grown for 45 days after the time of potting. During that time, greenhouse air temperature was maintained at $24 \pm 5^{\circ} \mathrm{C}$. Natural light was supplemented with grow lights $(1,000$ $\mathrm{W})$ set for a photoperiod of $16 \mathrm{~h}$ of light per day. Plants were watered every day for the first 7 days after potting by adding approximately $200 \mathrm{ml}$ of tap water to each Cone-tainer, as well as filling the aluminum trays with tap water. After that, plants were watered every other day by filling each aluminum tray with tap water. The LCO application treatments were made at the V2 growth stage (Fehr et al. 1971) using a $\mathrm{CO}_{2}$ backpack sprayer calibrated to deliver 187 liters/ha of spray solution. The LCO solution was applied at the earliest growth stage allowed by the label to represent the most realistic management situation (i.e., the LCO could be added to an early herbicide application). The LCO application consisted of using Rachet $\left(4 \times 10^{-7} \mathrm{M}\right.$ LCO concentration) at a labeled rate of $290 \mathrm{ml} / \mathrm{ha}$, and the control consisted of water only. At 7 days after the LCO application, plants were supplemented once a week for the remainder of the experiment with nutrients using Hoagland's number 2 basal salt mixture without ammonium phosphate at a rate of $1.51 \mathrm{~g} /$ liter of tap water. One-half liter of the nutrient solution was applied to each aluminum tray. At the end of the 45 days, plants were mostly at the beginning flowering growth stage (R1) and measured for height. After that, plants were removed from each Cone-tainer, and the shoots and roots were separated. Roots were washed to remove particulate matter. The roots of each plant were visually rated for the percentage of disease severity (i.e., the percentage of the root system with visual disease symptoms). Root disease symptoms appeared as dark brown to black lesions. The root system from each plant was individually immersed in water in a clear plastic tray and was scanned using a flatbed scanner (Perfection V700 photo scanner, Epson, Long Beach, CA) at 400 dpi with a pixel size of $0.063 \mathrm{~mm}$. The resulting images were analyzed using WinRhizo 2013 software (Regent Instruments, Quebec, Canada). For the image analysis, color classes were manually designated for the root system and the background. The data measurements collected using the image analysis included total root length, root surface area, and root volume. The software calculated these measurements based on Tennant's (Tennant 1975) statistical line intersect method (OrtizRibbing and Eastburn 2003).

After the plants had been scanned from each run of the experiment, two randomly chosen plants from each inoculation treatment were used to reisolate $F$. virguliforme. Isolations were also performed on "healthy" and "diseased" root tissue. Root sections, approximately $0.5 \mathrm{~cm}$ long, were surface disinfested with $95 \%$ ethanol and grown on potato dextrose agar for 14 days at $23 \pm 2{ }^{\circ} \mathrm{C}$ with 12 -h diurnal light. Morphological characteristics were then used to identify F. virguliforme (Leslie and Summerell 2006), which was recovered from diseased root tissue and not from the healthy root tissue (data not shown). Dry root and shoot mass data were then collected after air drying the plant parts at $60^{\circ} \mathrm{C}$ for 7 days.

At the start of each run of the experiment, two separate 10-g subsamples were collected from the combined cornmeal-sand medium prepared for each inoculation treatment. The same procedure was performed for each inoculation treatment after the cornmeal-sand medium was combined with the Metro Mix potting soil. From each subsample collected, $0.5 \mathrm{~g}$ was used to estimate the amount of inoculum present (Table 1). This estimation was done using the quantitative PCR (qPCR) methods outlined by Marburger et al. (2015). The forward primer (GCAGGCCATGTTGGTTCTGTA), reverse primer (GCACGTAAAGTGAGTCGTCTCATC), and TaqMan probe (6FAM-ACTCAGCGCCCAGGA-MGBNFQ) sequences targeted a 244bp region of the FvToxl gene of $F$. virguliforme. The qPCR program included initial denaturation at $95^{\circ} \mathrm{C}$ for 2 min followed by 40 cycles of $95^{\circ} \mathrm{C}$ for $10 \mathrm{~s}, 60^{\circ} \mathrm{C}$ for $20 \mathrm{~s}$, and $68^{\circ} \mathrm{C}$ for $30 \mathrm{~s}$.

\section{Experimental Design for Trials Examining S. sclerotiorum}

Sclerotia from a Wisconsin soybean isolate of S. sclerotiorum, collected in 2012 and designated isolate 20, were increased on carrot discs, harvested, and stored as dry sclerotia. Isolate 20 was characterized as $S$. sclerotiorum in molecular characterization and mycelial compatibility studies (Baturo-Ciesniewska et al. 2017; Willbur et al. 2017). Before inoculation, sclerotia were surface disinfested in $10 \%$ (v/v) bleach for $1 \mathrm{~min}$ followed by $95 \%$ ethanol for $1 \mathrm{~min}$. Sclerotia were then rinsed in sterile ultrapure Milli-Q water (EMD Millipore, Billerica, MA), blotted dry on sterile filter paper (Qualitative P8, porosity coarse, Fisher Scientific), and plated onto potato dextrose agar (dehydrated, Fisher Scientific). The inoculum was prepared by transferring a 5-mm agar plug from an actively growing PDA culture to a deep Petri plate (100 mm by $25 \mathrm{~mm}$; Lab-Tek Nunc, Sigma-Aldrich, Saint Louis, MO) of PDA. The inoculum was incubated for 3 to 4 days, or until sufficient leading-edge growth of active mycelium was obtained, at room temperature $\left(21\right.$ to $\left.24^{\circ} \mathrm{C}\right)$ before inoculation.

This experiment was conducted at the University of WisconsinMadison in a controlled-environment chamber from September to December in 2015. Two separate runs (i.e., repetitions) of this experiment were performed. For each run, the experimental design was a randomized complete block design with five replications of treatments arranged as a $2 \times 2$ factorial. Treatment factors consisted of two experimental soybean lines (91-38 and 91-44) and two LCO applications (water control and application of LCO solution) with a single S. sclerotiorum inoculation (isolate 20). A putative moderately resistant soybean experimental line, 91-38, and one susceptible experimental line, 91-44, were used based on preliminary S. sclerotiorum resistance screening (McCaghey et al. 2017). The soybean cyst nematode resistant line LN89-5717 (Nickell et al. 1994) and the partially SSR-resistant line W04-1002 (Peltier and Grau 2008) were crossed to generate these experimental lines. Seeds from these experimental lines were of the F8:12 generation and were highly inbred.

Soybean seeds were planted approximately $4 \mathrm{~cm}$ deep in $15.25-\mathrm{cm}$ diameter pots filled with moist potting mix (Sun Gro Horticulture). In the first repetition, 10 seeds of each line were planted one per pot, and 10 plants of each line were maintained for the water and LCO applications. In the second repetition, 16 seeds of each line were planted one per pot, and 10 were maintained for the foliar applications. The air temperature was maintained at $22^{\circ} \mathrm{C}$ during the day and $18^{\circ} \mathrm{C}$ at night in a 14-h photoperiod growth room. Plants were watered daily and fertilized once a week with $3.9 \mathrm{ml}$ of Miracle-Gro (Scotts MiracleGro Products, Marysville, $\mathrm{OH}$ ) in 1 liter of water. At the V2 growth stage, Rachet $\left(4 \times 10^{-7}\right.$ LCO concentration) was applied. Calibrated 16-oz spray bottles (Arrow Plastic Manufacturing, Elk Grove, IL) and a $150-\mathrm{mm}$ polypropylene powder funnel (Thermo Scientific, Nalge Nunc International, Penfield, NY) were used to evenly deliver $4.0 \mathrm{ml}$ of spray solution of $1.56 \mathrm{ml} /$ liter Rachet solution in deionized water to each plant. Deionized water was applied using the same method and rate to represent the control. Plants were then allowed to grow until the V4 growth stage before inoculation. 


\begin{tabular}{|c|c|c|c|c|c|}
\hline 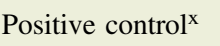 & $\ldots$ & $\ldots$ & 21.57 & 1.54 & $26,296,760$ \\
\hline 1 & NTC & Sand & N/A & N/A & 0 \\
\hline 1 & NTC & MM & N/A & N/A & 0 \\
\hline 2 & NIC & Sand & N/A & N/A & 0 \\
\hline 2 & NIC & MM & N/A & N/A & 0 \\
\hline 2 & $\mathrm{FV}$ & Sand & 25.19 & 1.19 & $2,246,600$ \\
\hline 2 & FV & MM & 28.46 & 0.79 & 244,220 \\
\hline
\end{tabular}

${ }^{\mathrm{s}} \mathrm{NIC}=$ noninoculated control; $\mathrm{FV}=$ inoculated with a mixture of three isolates of $F$. virguliforme.

${ }^{\mathrm{t}}$ Sand $=$ a mixture of the cornmeal-sand growth medium used to grow each isolate; $\mathrm{MM}=$ a combination of the cornmeal-sand medium prepared for each inoculation treatment with Metro Mix potting soil (Sun Gro Horticulture, Agawam, MA) in a ratio of 1 part cornmeal-sand medium to 3 parts potting soil.

${ }^{\mathrm{u}} \mathrm{Cq}=$ quantification cycle (i.e., the number of polymerase chain reaction cycles at which the target amplicon was quantified on based on the parameters outlined by Marburger et al. [2015]). The average represents two replications from each inoculation treatment and three technical replications used for the qPCR $(n=6)$.

${ }^{\mathrm{v}} \mathrm{Cq}$ std. dev. = quantification cycle standard deviation.

${ }^{w}$ Population estimate given in spores per gram of medium. Equations used to estimate are outlined by Marburger et al. (2015).

${ }^{x}$ Positive control $=$ DNA template used in the qPCR reaction was extracted from the $F$. virguliforme isolates used in this study.

${ }^{\mathrm{y}}$ Negative control $=$ autoclaved Milli-Q purified water used in place of DNA template.

${ }^{\mathrm{z}} \mathrm{N} / \mathrm{A}=$ not detected and quantified by the qPCR methods used.

Inoculations were conducted using the cut petiole technique described by Peltier and Grau (2008). A 1.5-cm-thick agar core of actively growing mycelia was collected using $1,000-\mu l$ pipet tips (Fisher Scientific). The second trifoliate petiole on each plant was excised to a length of $2.5 \mathrm{~cm}$. Pipet tips containing the inoculum were jabbed onto the cut petiole such that mycelia and cut tissue were in direct contact. Daily stem lesion measurements were collected using a digital caliper (Thermo Fisher Scientific, Waltham, MA) for 12 days postinoculation. The area under the disease progress curve (AUDPC) was used to assess disease severity over the 12-day epidemic (Madden et al. 2007).

\section{Statistical Analysis}

Experiments with $\boldsymbol{F}$. virguliforme. Mixed-model analysis of variance (ANOVA) was conducted using PROC GLIMMIX within SAS version 9.3 (SAS Institute, Cary, NC). Initial analyses revealed statistical differences between runs of the experiment for most growth measurements; however, further examination revealed these results were owing to differences in magnitude between the two runs for those growth characteristics. Therefore, the data from both runs of the experiment were combined for analysis. Models were constructed and analyzed individually for each growth characteristic measured. Percent disease severity values were transformed for analysis using the equation $\log _{10}$ ("severity" +1 ), and root volume values were transformed using the square root transformation. For all analyses, inoculation, LCO application, soybean cultivar, and all their interactions were considered fixed effects. Run, replication $\times$ inoculation(run), replication $\times$ inoculation $\times \operatorname{LCO}$ (run), and the overall error term were considered random effects. For all analyses, fixed effects were tested for significance at $\alpha=0.05$, and means comparisons of significant effects were calculated based on Fisher's protected least significant difference. The SLICE option in SAS was used to compare means of significant interactions (Littell et al. 2006).
Experiments with $S$. sclerotiorum. Mixed-model ANOVA was also conducted using PROC GLIMMIX within SAS version 9.4. Data from both runs of the experiment were combined for analysis. The gamma distribution was used with the standard LINK function to normalize AUDPC data, and the ILINK function was used to return back-transformed means, which are presented here. LCO application, experimental soybean line, and their interaction were considered fixed effects. A nested effect of replication and run and the overall error term were used as random effects. The Kenward-Roger method was used to calculate denominator degrees of freedom (Littell et al. 2006), and fixed effect differences were evaluated at $\alpha=0.05$.

\section{Characterizing LCO and $F$. virguliforme Interactions}

The LCO application and its interactions with the other treatment factors did not influence the plant height or above-ground characteristics (Table 2). The only significant effect on the above-ground measurements was related to shoot weight between the soybean cultivars (Table 2). The shoot weight for the cultivar Sloan was $3.62 \mathrm{~g}$ compared with $2.67 \mathrm{~g}$ for CH2105R2. Although the objective of this experiment was to evaluate SDS root disease symptoms, plants were also monitored for foliar SDS symptoms. During both runs of the experiment, respectively, only one and two of the inoculated plants for the cultivar Sloan exhibited some interveinal necrosis (data not shown). The remaining plants did not exhibit any foliar SDS symptoms.

As with the above-ground characteristics, the LCO application and its interactions with the other treatment factors did not affect any of the below-ground characteristics (Table 2). For percent root disease severity, inoculation was the only significant effect (Table 2). Back-transformed values showed that inoculating with $F$. virguliforme resulted in $16.1 \%$ severity compared with $0.4 \%$ severity for the noninoculated control.

For root weight, root length, root surface area, and root volume, there was evidence of an inoculation $\times$ cultivar interaction (Table 2). The cultivar Sloan showed greater root weight, root length, root 
surface area, and root volume compared with $\mathrm{CH} 2105 \mathrm{R} 2$ within the noninoculated control (Table 3 ). However, no difference between the two cultivars was observed for each characteristic within the $F$. virguliforme inoculated treatment. Inoculating with $F$. virguliforme resulted in decreased root length compared with the noninoculated control for the cultivar Sloan, but no difference was observed for $\mathrm{CH} 2105 \mathrm{R} 2$. Additionally, no significant decrease in root weight, root surface area, or root volume was observed for each cultivar when inoculated with $F$. virguliforme (Table 3 ).

These results suggested foliar-applied LCOs did not significantly impact soybean root rot caused by $F$. virguliforme. Application of LCOs in this experiment did not have an effect on above- and belowground early-season soybean growth measurements. Furthermore, the LCO application did not interact with any of the other treatment factors to influence any of these measurements. Because a significant effect was not found, the results of this study do not support results from previous studies suggesting the presence of Nod factors can induce soybean resistance (Duzan et al. 2005) or potentially lead to increased plant infection by the pathogen (Liang et al. 2013).

LCOs are commercially available in soybean inoculants that contain $B$. japonicum; however, LCO-only seed treatments are not commercially available to soybean producers. Because $F$. virguliforme infects soybean roots quickly after planting, LCOs applied as a seed treatment in combination with $B$. japonicum may provide different results. Some research has examined the role of rhizobia in controlling plant pathogens (Dakora 2003). Greenhouse experiments by Tu (1978) found root rot on soybean caused by Phytophthora megasperma was reduced when $B$. japonicum was applied to the potted soil immediately after planting. Follow-up experiments revealed $B$. japonicum reduced the sporulation of $P$. megasperma, Pythium ultimum, Ascochyta imperfecta, and Fusarium oxysporum by $75,65,35$, and $47 \%$, respectively ( $\mathrm{Tu} 1979$ ). Buonassisi et al. (1986) reported a reduction in root rot on snap bean caused by Fusarium solani f. sp. phaseoli when seeds were inoculated with Rhizobium and grown in pasteurized soil artificially infected with the pathogen. In field trials, Ehteshamul-Haque and Ghaffar (1993) found Sinorhizobium meliloti, R. leguminosarum, and B. japonicum reduced infection of Macrophomina phaseolina, Rhizoctonia solani, and Fusarium spp. in both leguminous plants such as soybean and mungbean (Vigna radiate [L.] R. Wilczek) and nonleguminous plants such assunflower (Helianthus annus L.) and okra (Abelmoschus esculentus [L.] Moench). Although there is evidence for reducing disease symptom development in the presence of rhizobia, the mechanisms for control are still not well understood. Tu (1979) suggested that decreased root rot was owing to rhizobia parasitizing the hyphal tips of the fungus, and therefore, contact with host plant cells was reduced. Dakora (2003) suggested other mechanisms may exist. The LCOs secreted by the rhizobia might have contributed to these results.

Even though there was no evidence that the LCO application affected soybean growth or root disease development, it is possible a response to the LCOs occurred immediately after the application (i.e., within the first 14 days or so after application). However, this may have been negated given the amount of time until the plant sampling, which occurred at approximately R1. Nevertheless, the product containing LCOs used in this study (Ratchet) is recommended for application between V2 and R1. Studying the effect of

\begin{tabular}{|c|c|c|c|}
\hline \multicolumn{4}{|c|}{$\begin{array}{c}\text { TABLE } 3 \\
\text { Inoculation } \times \text { cultivar interaction results for soybean root } \\
\text { weight, root length, root surface area, and root volume from } \\
\text { the Fusarium virguliforme experiment (all values presented } \\
\text { are the average on a per plant basis) }\end{array}$} \\
\hline \multirow[b]{2}{*}{ Variable } & \multirow[b]{2}{*}{ Inoculation $\mathbf{v}$} & \multicolumn{2}{|c|}{ Cultivarw } \\
\hline & & Sloan & CH2105R2 \\
\hline \multirow[t]{2}{*}{ Root weight (g) } & NIC & $1.49 \mathrm{aA}^{\mathrm{x}}$ & $1.05 \mathrm{bA}$ \\
\hline & $\mathrm{FV}$ & $1.36 \mathrm{aA}$ & $1.26 \mathrm{aA}$ \\
\hline \multirow[t]{2}{*}{ Root length ${ }^{\mathrm{y}}(\mathrm{cm})$} & NIC & $3,370 \mathrm{aA}^{\mathrm{x}}$ & $2,500 \mathrm{bA}$ \\
\hline & FV & $2,740 \mathrm{aB}$ & $3,020 \mathrm{aA}$ \\
\hline \multirow[t]{2}{*}{ Root surface $\operatorname{area}^{\mathrm{y}}\left(\mathrm{cm}^{2}\right)$} & NIC & $538 \mathrm{aA}^{\mathrm{x}}$ & $386 \mathrm{bB}$ \\
\hline & FV & $477 \mathrm{aA}$ & $514 \mathrm{aA}$ \\
\hline \multirow[t]{2}{*}{ Root volume ${ }^{\mathrm{y}, \mathrm{z}}\left(\mathrm{cm}^{3}\right)$} & NIC & $6.39 \mathrm{aA}^{\mathrm{x}}$ & $4.51 \mathrm{bA}$ \\
\hline & FV & $5.66 \mathrm{aA}$ & $6.16 \mathrm{aA}$ \\
\hline
\end{tabular}

${ }^{\mathrm{v}} \mathrm{NIC}=$ noninoculated control $; \mathrm{FV}=$ inoculated with $F$. virguliforme.

${ }^{\mathrm{w}} \mathrm{CH} 2105 \mathrm{R} 2$ is from Channel Brand (Monsanto, St. Louis, MO); Sloan is a public cultivar.

x Means comparisons were calculated based on Fisher's protected least significant difference. The SLICE option in SAS (version 9.3) was used to compare means of this significant interaction (Littell et al. 2006). Values followed by the same lowercase letter within a row (i.e., the inoculation treatment) or by the same uppercase letter within a column (i.e., cultivar) are not significantly different at $P \leq 0.05$.

${ }^{y}$ Root length, root surface area, and root volume values were obtained from digital image analysis using a WinRhizo 2013 root scanner system (Regent Instruments, Quebec, Canada).

${ }^{\mathrm{z}}$ Root volume values were transformed for analysis using the square root transformation. Back-transformed values are presented in this table.

\begin{tabular}{|c|c|c|c|c|c|c|c|}
\hline $\begin{array}{l}\text { Analysis of var } \\
\text { treatments (non }\end{array}$ & $\begin{array}{l}\text { results fo } \\
\text { llated con } \\
\text { ter contro }\end{array}$ & $\begin{array}{l}\text { oybean abo } \\
\text { and inoculk } \\
\text { d applicati }\end{array}$ & $\begin{array}{r}\text { TABL } \\
\text { and below-grc } \\
\text { with Fusarium } \\
\text { of LCOs), and t }\end{array}$ & $\begin{array}{l}\text { growth } \\
\text { uliforme), } \\
\text { soybean }\end{array}$ & $\begin{array}{l}\text { cteristics } \\
\text { lipo-chito } \\
\text { ars (Sloan }\end{array}$ & $\begin{array}{l}\text { ofluenced by ty } \\
\text { osaccharide (LC } \\
\text { d CH2105R2) }\end{array}$ & $\begin{array}{l}\text { noculation } \\
\text { applications }\end{array}$ \\
\hline Source of variation & Plant height & Shoot weight & Disease severityy & Root weight & Root length & Root surface area & Root volume $e^{z}$ \\
\hline Inoculation (I) & 0.0983 & 0.9585 & $<0.0001$ & 0.7014 & 0.8005 & 0.4436 & 0.4797 \\
\hline Cultivar (C) & 0.0912 & $<0.0001$ & 0.4883 & 0.0014 & 0.1488 & 0.1165 & 0.1523 \\
\hline $\mathrm{I} \times \mathrm{C}$ & 0.2717 & 0.2086 & 0.8576 & 0.0431 & 0.0059 & 0.0152 & 0.0270 \\
\hline $\mathrm{LCO} \times \mathrm{C}$ & 0.0936 & 0.1372 & 0.4455 & 0.1566 & 0.2083 & 0.4338 & 0.4149 \\
\hline $\mathrm{I} \times \mathrm{LCO} \times \mathrm{C}$ & 0.4844 & 0.3121 & 0.3932 & 0.4243 & 0.3252 & 0.2865 & 0.3943 \\
\hline
\end{tabular}

y Disease severity values were transformed for analysis using the equation $\log _{10}$ ("severity" +1 ).

${ }^{\mathrm{z}}$ Root volume values were transformed for analysis using the square root transformation. 
LCOs has primarily focused on early plant growth and crop establishment, but under ideal plant growth conditions (e.g., greenhouse conditions), improving early growth using LCOs may not be advantageous. Additionally, the probability of observing a response to LCO applications may be greater when early crop establishment is difficult or limiting.

Inoculating with $F$. virguliforme can result in foliar symptoms on young, susceptible plants (Tande et al. 2014). The estimated population (i.e., spores/g of medium) for $F$. virguliforme using qPCR methods (Table 1) was significantly higher than the estimated populations of $10^{2}$ to $10^{3}$ colony-forming units per gram of soil isolated from dilution plating methods that have been reported from symptomatic soybean plants in other studies (Mbofung et al. 2011; Rupe et al. 1997; Scherm et al. 1998). Even with the population estimates in this study, foliar SDS symptoms were not expected to be observed by the plant sampling time, which occurred 45 days after planting. However, a few plants for the cultivar Sloan did express foliar symptoms during this experiment. The qPCR methods described by Marburger et al. (2015) and used to quantify the amount of inoculum in this study have not been correlated to root and foliar SDS disease symptoms, though. Despite this, the percent root disease severity did not differ between the Sloan and CH2105R2 cultivars. Although the root measurements for the cultivar Sloan were greater than $\mathrm{CH} 2105 \mathrm{R} 2$ within the noninoculated treatment, there was no difference in the root measurement characteristics when each was inoculated with $F$. virguliforme. It is hypothesized that CH2105R2 would exhibit less SDS foliar symptoms than Sloan if the experiment was carried out until the mid to late reproductive stages (i.e., R4 to R7). In a field study conducted in Wisconsin, the CH2105R2 cultivar was among only two of 10 cultivars examined that consistently exhibited the least amount of SDS foliar symptom development at the R5 to R7 growth stages.

\section{Characterizing LCO and S. sclerotiorum Interactions}

Characteristic SSR lesions were observed on both the moderately resistant and susceptible soybean lines. Line 91-38 (moderately resistant) exhibited a mean lesion length of $49.8 \mathrm{~mm}$, and line 91-44 (susceptible) exhibited a mean lesion length of $83.7 \mathrm{~mm}$. The interaction between LCO application and soybean experimental line on SSR severity was not significant $(P=0.33)$. Soybean line $(P=0.01)$ and LCO application $(P=0.02)$, however, significantly affected AUDPC. The interaction term, therefore, was removed from the analysis, and fixed effects of application and line were reevaluated. The moderately resistant line 91-38 exhibited significantly fewer symptoms than the susceptible line $91-44(P=0.01)$ (Fig. 1). Furthermore, the LCO application resulted in significantly higher AUDPC values than the water control application $(P=0.03)$ (Fig. 2). As indicated by the insignificant interaction, disease levels by LCO application were not dependent on putative SSR resistance within the lines.

To our knowledge, this is the first report characterizing the effects of foliar LCO application on SSR development in soybean. Although the LCO application resulted in a significantly higher AUDPC value, it is recognized that the application rate was 10 times the amount specified on the product label. Because the product contains naturally occurring LCOs formulated for corn and soybean, the label rate may not accurately reflect the concentrations that could be present in the soil postapplication. Therefore, the potentially adverse effects of these LCO applications on field-grown soybeans should be considered despite the higher rate used. LCO application effects on soybean gene expression have been previously studied (Lindsay 2007; Wang et al. 2012); however, the effects of LCO applications on soybean pathogens and subsequent disease development have not been well studied. Wang et al. (2012) identified defense-related gene products, including chitinases, which are up-regulated $48 \mathrm{~h}$ after a foliar LCO application on stressed soybeans. Chitinases are known to both enhance host disease resistance and inhibit host defense responses in rhizobial interactions. In other studies, foliar LCO applications on soybean under optimal conditions did not affect chitinase or $\beta$-1,3-glucanase activity but did lead to an increase in salicylate levels (Lindsay 2007). Additionally, an LCO-activated gene in Medicago truncatula, ripl, was found to stimulate the localized and rapid production of ROS (Ramu et al. 2002). Surprisingly, other studies have reported a decrease of ROS production in response to Nod factors (Lohar et al. 2007; Shaw and Long 2003). This paradox may be owing to a very dynamic ROS response to Nod factors with a rapid increase followed by a decrease of ROS production, as shown in $P$. vulgaris by Cárdenas et al. (2008). These LCO application effects could potentially reduce plant infection by the pathogen and disease development through increased host immunity. However, these interactions have not been studied in soybean.

In another study, the structurally related COs were shown to inhibit infection of B. napus plants by S. sclerotiorum (Yin et al. 2013). These COs increased cytosolic $\mathrm{Ca}^{2+}$, nitric oxide, and hydrogen peroxide levels, which led to the reduction of symptoms in planta. In soybean, however, LCO application does not seem to inhibit plant infection by $S$. sclerotiorum and results in increased SSR lesion development. Oxalic acid, which is a key pathogenicity factor of $S$. sclerotiorum, is known to induce ROS production, which promotes host programmed cell death and disease (Kim et al. 2008; Ranjan et al. in press; Williams et al. 2011). Although ROS is typically a host defense response, the complex necrotrophic nature of $S$. sclerotiorum may enable this pathogen to thrive in an ROSelevated environment. Further studies characterizing the mechanism of localized LCO activity on S. sclerotiorum and SSR development, however, must be conducted to understand this interaction better.

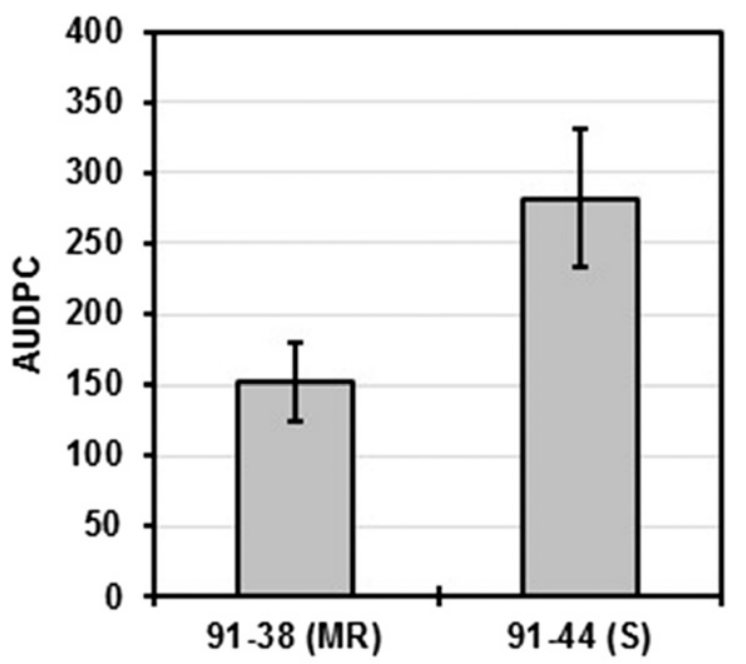

Experimental Soybean Lines

\section{FIGURE 1}

Response of soybean experimental cultivars 91-38 (moderately resistant, MR) and 91-44 (susceptible, S) to Sclerotinia sclerotiorum inoculation determined by the area under the disease progress curve (AUDPC). Daily stem lesion $(\mathrm{mm})$ measurements were collected for 12 days postinoculation. Bars represent the mean values of five replications and two runs (i.e., repetitions) of the experiment. Error bars represent the standard error of the mean. Line 91-44 exhibited significantly more symptom development than line 91-38 $(P=0.01)$ 


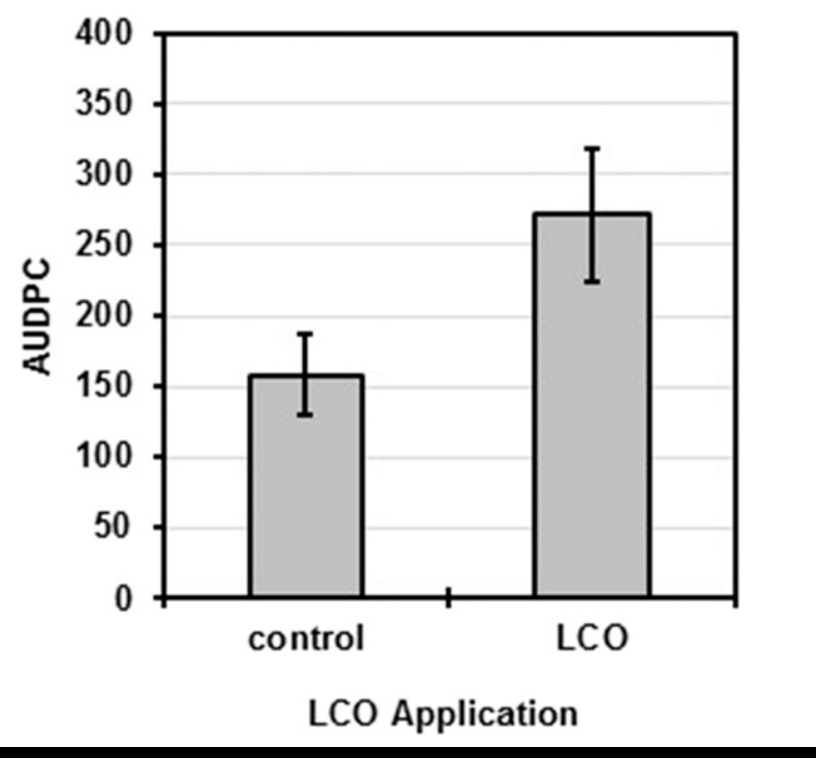

FIGURE 2

Soybean lipo-chitooligosaccharide (LCO) application effect on Sclerotinia sclerotiorum inoculation determined by the area under the disease progress curve (AUDPC). Daily stem lesion ( $\mathrm{mm}$ ) measurements were collected for 12 days postinoculation. Bars represent the mean values of five replications and two runs (i.e., repetitions) of the experiment. Error bars represent the standard error of the mean. LCO applications resulted in significantly more symptom development than water control applications $(P=0.03)$.

More comprehensive in vivo and in planta investigations should consider LCO effects on fungal growth and development as well as the long-term changes in soybean after foliar application. S. sclerotiorum inoculations were conducted nearly 2 weeks after LCO application, and it is difficult to determine what changes may persist long enough to affect plant infection by $S$. sclerotiorum. In the field, infection occurs near soybean flowering (the R1 growth stage), and the LCO applications are recommended between the $\mathrm{V} 2$ and $\mathrm{R} 1$ growth stages. Additional studies of application timing and subsequent infection could identify which timings most strongly affect plant infection by $S$. sclerotiorum and may help reduce unintended SSR symptom development.

\section{Conclusions}

This study was the first attempt at characterizing LCO interactions on early disease symptom development of soybean SDS, caused by $F$. virguliforme, and SSR, caused by S. sclerotiorum. Our null hypotheses were (i) foliar application of LCOs will not affect early soybean root disease symptom development caused by $F$. virguliforme and (ii) foliar application of LCOs will not increase early soybean stem symptoms caused by $S$. sclerotiorum. Considering the evidence presented here, we accept null hypothesis one and reject null hypothesis two. Foliar-applied LCOs did not significantly impact soybean root disease development or early-season above- and belowground growth characteristics in the $F$. virguliforme experiment. However, foliar-applied LCOs significantly affected soybean stem lesion development by $S$. sclerotiorum. These results indicate that foliar-applied LCOs as a soybean management practice would not increase or decrease early disease symptom development from $F$. virguliforme, but foliar LCOs may stimulate changes in soybean that affect SSR symptom development up to 2 weeks following application. More studies are required to elucidate the mechanisms of these LCO-host-pathogen interactions in soybean. Because $F$. virguliforme infects soybean early in the growing season after planting, examining seed-applied rhizobia inoculants that contain LCOs may provide further insight into LCOs as promoters or inhibitors of SDS root symptom development. Foliar LCOs applied at the beginning flowering growth stage would also provide further insight into stem lesion development caused by S. sclerotiorum.

\section{Acknowledgments}

The authors thank Craig Grau for the use of his soybean breeding lines and Carol Groves and Laurie Gerber for their technical assistance and support in conducting this research.

\section{Literature Cited}

Baturo-Ciesniewska, A., Groves, C. L., Albrecht, K. A., Grau, C. R., Willis, D. K., and Smith, D. L. 2017. Molecular identification of Sclerotinia trifoliorum and Sclerotinia sclerotiorum isolates from the United States and Poland. Plant Dis. 101:192-199.

Boland, G. J., and Hall, R. 1994. Index of plant hosts of Sclerotinia sclerotiorum. Can. J. Plant Pathol. 16:93-108.

Bradley, C. A., Allen, T., and Esker, P. D. 2017. Estimates of soybean yield reductions caused by diseases in the United States. University of Illinois Department of Crop Science Extension Outreach. Online publication. http:// extension.cropsciences.illinois.edu/fieldcrops/diseases/yield_reductions.php.

Buonassisi, A. J., Copeman, R. J., Pepin, H. S., and Eaton, G. W. 1986. Effect of Rhizobium spp. on Fusarium solani f. sp. phaseoli. Can. J. Plant Pathol. 8: $140-146$

Cárdenas, L., Martínez, A., Sánchez, F., and Quinto, C. 2008. Fast, transient and specific intracellular ROS changes in living root hair cells responding to Nod factors (NFs). Plant J. 56:802-813.

Cesco, S., Neumann, G., Tomasi, N., Pinton, R., and Weisskopf, L. 2010. Release of plant-borne flavonoids into the rhizosphere and their role in plant nutrition. Plant Soil 329:1-25.

Channel. 2014. Channel soybean seed guide. Monsanto, St. Louis, MO. Online publication. https://www.channel.com/about/products/Documents/ 2014ChannelSeedGuideSoybean.pdf.

Dakora, F. D. 2003. Defining new roles for plant and rhizobial molecules in sole and mixed plant cultures involving symbiotic legumes. New Phytol. 158: 39-49.

Duzan, H. M., Mabood, F., Zhou, X., Souleimanov, A., and Smith, D. L. 2005. Nod factor induces soybean resistance to powdery mildew. Plant Physiol. Biochem. 43:1022-1030.

Ehteshamul-Haque, S., and Ghaffar, A. 1993. Use of rhizobia in the control of root rot diseases of sunflower, okra, soybean and mungbean. J. Phytopathol. 138:157-163.

Fehr, W. R., Caviness, C. E., Burmood, D. T., and Pennington, J. S. 1971. Stage of development descriptions for soybeans, Glycine max (L.) Merrill. Crop Sci. 11:929-931.

Gough, C., and Cullimore, J. 2011. Lipo-chitooligosaccharide signaling in endosymbiotic plant-microbe interactions. Mol. Plant-Microbe Interact. 24: 867-878.

Grau, C. R., and Hartman, G. L. 2015. Compendium of Soybean Diseases, 5th Ed. G. L. Hartman, J. C. Rupe, E. J. Sikora, L. L. Domier, J. A. Davis, and K. L. Steffey, eds. American Phytopathological Society, St. Paul, MN.

Hartman, G. L., Leandro, L. F. S., and Rupe, J. C. 2015. Sudden death syndrome. Pages 88-90 in: Compendium of Soybean Diseases and Pests. G. L. Hartman, J. C. Rupe, E. F. Sikora, L. L. Domier, J. A. David, and K. L. Steffey, eds. American Phytopathological Society, St. Paul, MN.

Kim, K. S., Min, J.-Y., and Dickman, M. B. 2008. Oxalic acid is an elicitor of plant programmed cell death during Sclerotinia sclerotiorum disease development. Mol. Plant-Microbe Interact. 21:605-612.

Koenning, S. R., and Wrather, J. A. 2010. Suppression of soybean yield potential in the continental United States by plant diseases from 2006 to 2009. Plant Health Prog. Online publication.

Leandro, L. F., Tatalovic, N., and Luckew, A. 2012. Soybean sudden death syndrome-Advances in knowledge and disease management. CAB Rev. 7: $1-14$.

Leslie, J. F., and Summerell, B. A., eds. 2006. The Fusarium Laboratory Manual, 1st Ed. Blackwell Publishing, Ames, IA.

Liang, Y., Cao, Y., Tanaka, K., Thibivilliers, S., Wan, J., Choi, J., Kang, C. H., Qui, J., and Stacey, G. 2013. Nonlegumes respond to rhizobial nod factors by suppressing the innate immune response. Science 341:1384-1387. 
Lindsay, J. K. 2007. The effect of lipo-chitooligosaccharide from Bradyrhizobium japonicum, on soybean salicylic acid, pathogenesis-related protein activity and gene expression. M.S. thesis, McGill University, Montreal, Canada.

Littell, R. C., Milliken, C. A., Stroup, W. W., Wolfinger, R. D., and Schabenberger, O. 2006. SAS for Mixed Models, 2nd Ed. SAS, Cary, NC.

Lohar, D. P., Haridas, S., Gantt, J. S., and Vandenbosch, K. A. 2007. A transient decrease in reactive oxygen species in roots leads to root hair deformation in the legume-rhizobia symbiosis. New Phytol. 173:39-49.

Madden, L. V., Hughes, G., and van den Bosch, F. 2007. The Study of Plant Disease Epidemics. American Phytopathological Society, St. Paul, MN.

Maillet, F., Poinsot, V., André, O., Puech-Pagès, V., Haouy, A., Gueunier, M., Cromer, L., Giraudet, D., Formey, D., Niebel, A., Martinez, E. A., Driguez, H., Bécard, G., and Dénarié, J. 2011. Fungal lipochitooligosaccharide symbiotic signals in arbuscular mycorrhiza. Nature 469:58-63.

Mandal, S. M., Chakraborty, D., and Dey, S. 2010. Phenolic acids act as signaling molecules in plant-microbe symbioses. Plant Signal. Behav. 5: 359-368.

Marburger, D. A., Venkateshwaran, M., Conley, S. P., Esker, P. D., Lauer, J. G., and Ané, J. 2015. Crop rotation and management effect on Fusarium spp. populations. Crop Sci. 55:365-376.

Mbofung, G. C. Y., Fessehaie, A., Bhattacharyya, M. K., and Leandro, L. F. S. 2011. A new TaqMan real-time polymerase chain reaction assay for quantification of Fusarium virguliforme in soil. Plant Dis. 95:1420-1426.

McCaghey, M., Willbur, J., Ranjan, A., Grau, C. R., Chapman, S., Diers, B., Groves, C., Kabbage, M., and Smith, D. L. 2017. Development and evaluation of Glycine max germplasm lines with quantitative resistance to Sclerotinia sclerotiorum. Front. Plant Sci. 8:1485.

McLean, K. S., and Lawrence, G. W. 1993. Interrelationship of Heterodera glycines and Fusarium solani in sudden death syndrome of soybean. J. Nematol. 25:434-439.

Navi, S. S., and Yang, X. B. 2008. Foliar symptom expression in association with early infection and xylem colonization by Fusarium virguliforme (formerly $F$. solani $\mathrm{f}$. sp. glycines), the causal agent of soybean sudden death syndrome. Plant Health Prog. Online publication.

Nickell, C. D., Noel, G. R., Bernard, R. L., Thomas, D. J., and Frey, K. 1994. Registration of soybean germplasm line LN89-5717, resistant to soybean cyst nematode. Crop Sci. 34:1133.

Ortiz-Ribbing, L. M., and Eastburn, D. M. 2003. Evaluation of digital image acquisition methods for determining soybean root characteristics. Crop Manage. Online publication.

Peltier, A. J., Bradley, C. A., Chilvers, M. I., Malvick, D. K., Mueller, D. S., Wise, K. A., and Esker, P. D. 2012. Biology, yield loss and control of Sclerotinia stem rot of soybean. J. Integr. Pest Manag. 3:1-7.

Peltier, A. J., and Grau, C. R. 2008. The influence of light on relationships between Sclerotinia stem rot of soybean in field and controlled environments. Plant Dis. 92:1510-1514.

Ramu, S. K., Peng, H. M., and Cook, D. R. 2002. Nod factor induction of reactive oxygen species production is correlated with expression of the early nodulin gene rip1 in Medicago truncatula. Mol. Plant-Microbe Interact. 15: 522-528.

Ranjan, A., Jayaraman, D., Grau, C., Hill, J. H., Whitham, S. A., Ane, J., Smith, D. L., and Kabbage, M. In press. The pathogenic development of Sclerotinia sclerotiorum in soybean requires specific host NADPH oxidases. Mol. Plant Pathol. doi.org/10.1111/mpp.12555.

Rupe, J. C., Robbins, R. T., and Gbur, E. E. 1997. Effect of crop rotation on soil population densities of Fusarium solani and Heterodera glycines and on the development of sudden death syndrome of soybean. Crop Prot. 16: 575-580.
Scherm, H., Yang, X. B., and Lundeen, P. 1998. Soil variables associated with sudden death syndrome in soybean fields in Iowa. Plant Dis. 82:1152-1157.

Shaw, S. L., and Long, S. R. 2003. Nod factor inhibition of reactive oxygen efflux in a host legume. Plant Physiol. 132:2196-2204.

Smith, D. L., Prithiviraj, B., and Zhang, F. 2002. Rhizobial signals and control of plant growth. Pages 327-330 in: Nitrogen Fixation: Global Perspectives. T. M. Finan, M. R. O'Brian, D. B. Layzell, K. Vessey, and W. E. Newton, eds. CABI, Wallingford, UK.

Spaink, H. P. 1996. Regulation of plant morphogenesis by lipo-chitinoligosaccharide. Crit. Rev. Plant Sci. 15:559-582.

Sun, J., Miller, J. B., Granqvist, E., Wiley-Kalil, A., Gobbato, E., Maillet, F., Cottaz, S., Samain, E., Venkateshwaran, M., Fort, S., Morris, R. J., Ané, J. M., Dénarié, J., and Oldroyd, G. E. D. 2015. Activation of symbiosis signalling by arbuscular mycorrhizal fungi in legumes and rice. Plant Cell 27:823-838.

Tande, C., Hadi, B., Chowdhury, R., Subramanian, S., and Byamukama, E. 2014. First report of sudden death syndrome of soybean caused by Fusarium virguliforme in South Dakota. Plant Dis. 98:1012.

Tennant, D. 1975. A test of the modified line intersect method for estimating root length. J. Ecol. 63:995-1001.

Tu, J. C. 1978. Protection of soybean from severe Phytophthora root rot by Rhizobium. Physiol. Plant Pathol. 12:233-240.

$\mathrm{Tu}$ J. C. 1979. Evidence of differential tolerance among some root rot fungi to rhizobial parasitism in vitro. Physiol. Plant Pathol. 14:171-177.

Venkateshwaran, M., Volkening, J. D., Sussman, M. R., and Ané, J. M. 2013. Symbiosis and the social network of higher plants. Curr. Opin. Plant Biol. 16: 118-127.

Wang, J., Jacobs, J. L., Byrne, J. M., and Chilvers, M. 2015. Improved diagnoses and quantification of Fusarium virguliforme, causal agent of soybean sudden death syndrome. Phytopathol. 105:378-387.

Wang, N., Khan, W., and Smith, D. L. 2012. Changes in soybean global gene expression after application of lipo-chitooligosaccharide from Bradyrhizobium japonicum under sub-optimal temperature. PLoS One 7:e31571.

White, T. J., Bruns, T., Lee, S., and Taylor, J. W. 1990. Amplification and direct sequencing of fungal ribosomal RNA genes for phylogenetics. Pages 315-322 in: PCR Protocols: A Guide to Methods and Applications. M. A. Innis, D. H. Gelfand, J. J. Sninsky, and T. J. White, eds. Academic Press, San Diego, CA.

Willbur, J. F., Ding, S., Marks, M. E., Lucas, H., Grau, C. R., Groves, C. L., Kabbage, M., and Smith, D. L. 2017. Comprehensive Sclerotinia stem rot screening of soybean germplasm requires multiple isolates of Sclerotinia sclerotiorum. Plant Dis. 101:344-353.

Williams, B., Kabbage, M., Kim, H.-J., Britt, R., and Dickman, M. B. 2011. Tipping the balance: Sclerotinia sclerotiorum secreted oxalic acid suppresses host defenses by manipulating the host redox environment. PLoS Pathog 7:e1002107.

Wrather, J. A., and Koenning, S. R. 2009. Effects of diseases on soybean yields in the United States 1996 to 2007. Plant Health Prog. Online publication.

Xie, Z. P., Staehelin, C., Vierheilig, H., Wiemken, A., Jabbouri, S., Broughton, W. J., Vogeli-Lange, R., and Boller, T. 1995. Rhizobial nodulation factors stimulate mycorrhizal colonization of nodulating and nonnodulating soybeans. Plant Physiol. 108:1519-1525.

Yin, H., Li, Y., Zhang, H.-Y., Wang, W.-X., Lu, H., Grevsen, K., Zhao, X., and Du, Y. 2013. Chitosan oligosaccharides-triggered innate immunity contributes to oilseed rape resistance against Sclerotinia sclerotiorum. Int. J. Plant Sci. 174:722-732.

Zhang, F., and Smith, D. L. 2002. Interorganismal signalling in suboptimum environments: The legume-rhizobia symbiosis. Adv. Agron. 76:125-161.

Ziems, A. D., Giesler, L. J., and Yuen, G. Y. 2006. First report sudden death syndrome of soybean caused by Fusarium solani f. sp. glycines in Nebraska. Plant Dis. 90:109. 